\title{
Total Synthesis of (-)- Mitrephorone A Enabled by Stereoselective Nitrile Oxide Cycloaddition and Tetrasubstituted Olefin Synthesis
}

\section{Journal Article}

Author(s):

Schneider, Michael; Richter, Matthieu J.R.; Carreira, Erick M. (D)

Publication date:

2020-10-14

\section{Permanent link:}

https://doi.org/10.3929/ethz-b-000448043

\section{Rights / license:}

Creative Commons Attribution-NonCommercial-NoDerivatives 4.0 International

\section{Originally published in:}

Journal of the American Chemical Society 142(41), https://doi.org/10.1021/jacs.0c09520

Funding acknowledgement:

833540 - Development of Stereoselective Olefin Functionalization Methods (EC) 


\title{
Total Synthesis of (-)-Mitrephorone A Enabled by Stereoselective Nitrile Oxide Cycloaddition and Tetrasubstituted Olefin Synthesis
}

\author{
Michael Schneider, Matthieu J. R. Richter, and Erick M. Carreira* \\ Cite This: J. Am. Chem. Soc. 2020, 142, 17802-17809 \\ Read Online
}

ABSTRACT: A highly enantioselective and diastereoselective total synthesis of the diterpenoid (-)-mitrephorone $\mathrm{A}$ is presented. Key to the synthesis are stereocontrolled 1,4-semihydrogenation of a 1,3-diene to a tetrasubstituted double bond, enzyme-catalyzed malonate desymmetrization, and highly diastereoselective nitrile oxide cycloaddition. The streamlined strategy is a considerable improvement to those reported earlier in

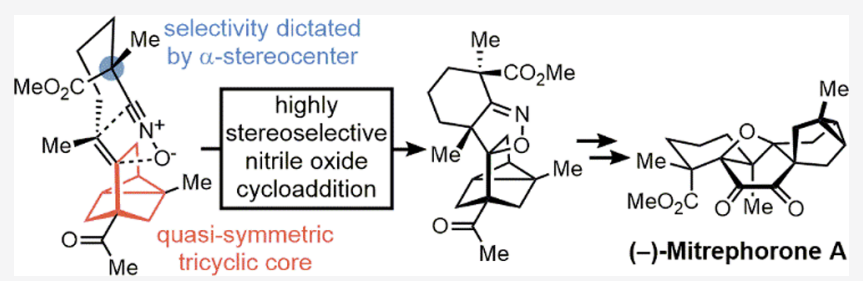
terms of diastereo- and enantioselectivity. For the first time, the combination of modern Pd-cross-coupling with Cr-catalyzed reduction allows for rapid access to tetrasubstituted olefins with full stereocontrol.

\section{INTRODUCTION}

(-)-Mitrephorone A (1) is a trachylobane natural product characterized by a pentacyclic carbon skeleton, which includes a tricyclo[3.2.1.0 $0^{2,7}$ octane (Scheme 1$)^{1,2}$ The carbon framework of 1 encompasses at the core a unique fully substituted oxetane. Its five contiguous stereocenters along with its complex caged structure render $\mathbf{1}$ a formidable target for stereoselective synthesis. ${ }^{3,4}$ In addition to synthetic challenges, (-)-mitrephorone A (1) exhibits cytostatic activity against a number of bacterial and fungal pathogens as well as cytotoxicity against selected cancer cell lines (MCF-7, H460, SF-268). ${ }^{1,2,5}$

We have previously reported the first and enantioselective total synthesis of (-)-mitrephorone A (1), which lacked diastereocontrol. ${ }^{3}$ Herein, we report a new route for a highly enantio- and diastereoselective synthesis of 1 . Our retrosynthetic analysis involved disconnection of (-)-mitrephorone A (1) to 2 (Scheme 1). The 1,3-relationship of ketone and tertiary alcohol in $\mathbf{2}$ is a partial retron for a nitrile oxide cycloaddition strategy via isoxazoline 3 . $^{6}$ We wondered whether the stereogenic center $\alpha$ to the nitrile oxide in $\mathbf{4}$ would lead to control over facial selectivity in an intramolecular dipolar cycloaddition reaction $(4 \rightarrow 3)$. A key requirement of this approach is the stereoselective synthesis of the tetrasubstituted olefin embedded in 4. Although traditional approaches to such an olefin might feature condensation reactions of the corresponding tricyclic ketone, we envisioned a different strategy involving diene $\mathbf{5}$. At the outset, it was not clear how we would control the configuration of a tetrasubstituted olefin. The approach we describe reveals an effective solution to the synthesis of tetrasubstituted olefins, enabling diastereoselective functionalization of chiral tricyclo[3.2.1.0 $\left.0^{2,7}\right]$ octanes and related structures. More broadly, the new retrosynthetic plan outlined in Scheme 1 leads to novel stereodefined strategies to the caged structure of (-)-mitrephorone A (1) and other trachylobanes.

The successful use of olefin 4 in our synthesis requires control over both facial selectivity and olefin geometry. To address the former, we conceived of an approach involving an intramolecular annulation reaction. The strategic design of precursors such as $\mathbf{9}$ includes a resident stereogenic center $(*)$ along the connecting backbone as a stereochemical controlling feature (Scheme 2). In addressing the latter, it is important to note that addition reactions to tetrasubstituted olefin 9 set two stereocenters, and olefin geometry dictates their relative configuration $((E)-\mathbf{9} \rightarrow \mathbf{1 0}$ vs $(Z)-\mathbf{9} \rightarrow \mathbf{1 1})$.

\section{RESULTS AND DISCUSSION}

Olefin Synthesis. There are numerous methods available for ketone olefination en route to 4 (Scheme 1). In our initial studies, we tested several approaches for olefin synthesis from tricyclo[3.2.1.0 $\left.0^{2,7}\right]$ octanone 12 (Scheme 3$) .^{7}$ The tetrasubstituted alkenes we envisioned synthesizing feature two structural elements that render their stereoselective synthesis challenging: (1) They include an allylic quaternary center, which can reduce reactivity of olefin precursors, and (2) methyl and methylenes at one end of the olefin can be sterically challenging to differentiate when controlling olefin geometry. Initial attempts employing Wittig and HornerWadsworth-Emmons olefinations ${ }^{8}$ as well as McMurry

Received: September 4, 2020

Published: October 6, 2020 
Scheme 1. (-)-Mitrephorone A (1) and Retrosynthetic Analysis

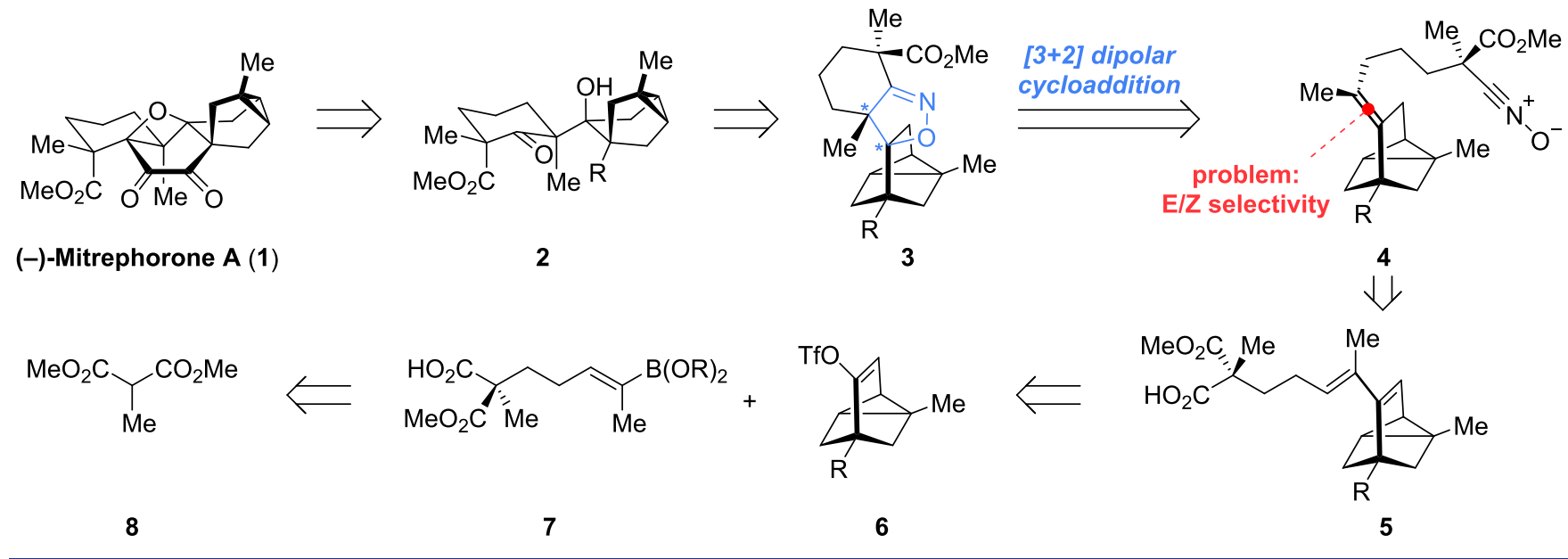

couplings ${ }^{9}$ did not afford any tetrasubstituted olefins. Claisen rearrangements have been previously employed in the stereoselective synthesis of tetrasubstituted alkenes. ${ }^{10}$ To this end, we transformed hydroxyketone 12 (95\% ee) into allylic acetate 15 in three steps and $40 \%$ yield as 1.2:1 mixture of diastereomers (Scheme 3). Ireland-Claisen rearrangement was induced by treatment of 15 with LiHMDS, TBSCl, and HMPA, ${ }^{11}$ and after treatment with methyl iodide and potassium carbonate, ester 16 was obtained in $87 \%$ yield as a 2.3:1 mixture of diastereomers. After reduction using DIBAL-H, the two double bond isomers were separated and assigned via $2 \mathrm{D}$ NOESY NMR experiments (see the Supporting Information (SI) for details). Further attempts to optimize the diastereoselectivity in the Ireland-Claisen reaction by employing different silyl groups did not lead to improvement. As we opted for a highly stereoselective synthesis, we subsequently envisioned different routes to the tetrasubstituted olefin not involving nucleophilic addition to tricyclic ketones.

Stereocontrolled preparation of tetrasubstituted olefins has been a longstanding challenge in organic synthesis. ${ }^{8,12} \mathrm{~A}$ conceptually new route to tetrasubstituted olefin $\mathbf{4}$ would require stereoselective reduction of the diene in $\mathbf{5}$ in a catalystcontrolled process (Scheme 1). 1,3-Dienes may be conveniently accessed via palladium-catalyzed $\mathrm{sp}^{2}-\mathrm{sp}^{2}$ cross-coupling.

Scheme 2. Stereochemical Considerations Associated with Olefin Functionalization

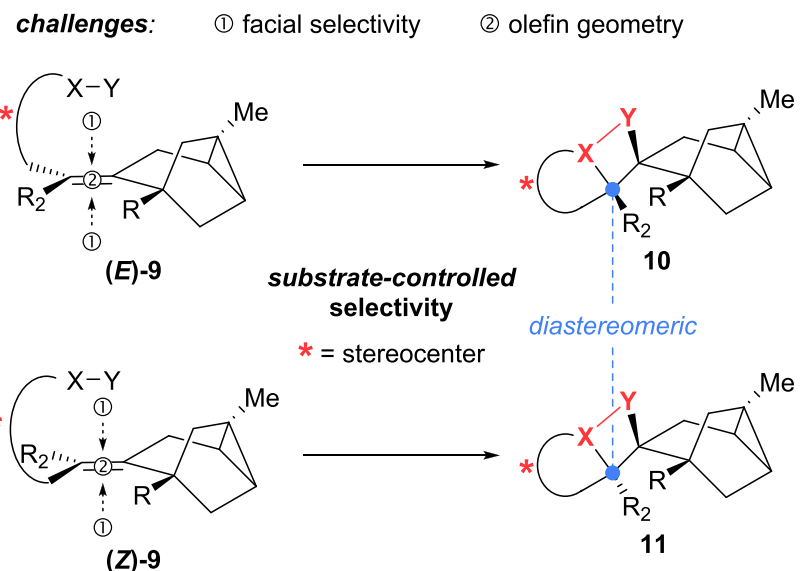

Scheme 3. Synthesis of Tetrasubstituted Olefin via IrelandClaisen Rearrangement ${ }^{a}$
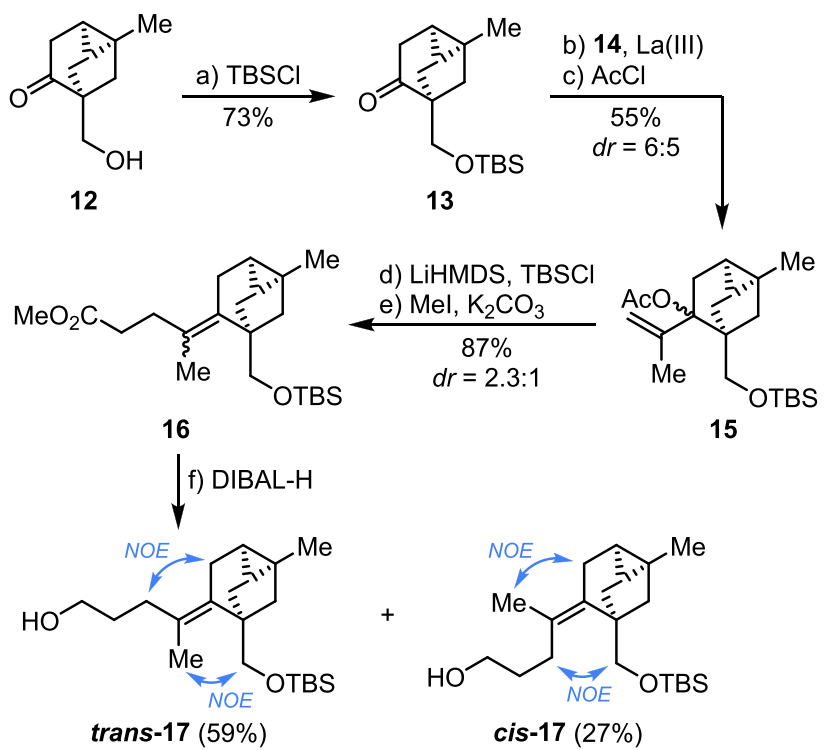

${ }^{a}$ Reagents and conditions: (a) TBSCl, imidazole, DMAP, $\mathrm{CH}_{2} \mathrm{Cl}_{2}$, r.t., $73 \%$; (b) isopropenylmagnesium bromide (14), $\mathrm{LaCl}_{3} \cdot 2 \mathrm{LiCl}$, THF, then $13,0{ }^{\circ} \mathrm{C}$ to r.t., $86 \%, d r=6: 5$; (c) $\mathrm{PhNMe}_{2}, \mathrm{AcCl}, 50{ }^{\circ} \mathrm{C}, 64 \%$; (d) LiHMDS, TBSCl, HMPA, THF, $-78{ }^{\circ} \mathrm{C}$ to r.t., then $1 \mathrm{M} \mathrm{HCl}$; (e) $\mathrm{MeI}, \mathrm{K}_{2} \mathrm{CO}_{3}, \mathrm{DMF}$, r.t., $87 \%$ over two steps, $d r=2.3: 1$; (f) DIBAL-H, PhMe, $-78{ }^{\circ} \mathrm{C}$ to r.t., $59 \%$ trans $-17,27 \%$ cis- 17 .

Transition-metal-catalyzed semireductions of dienes by $\mathrm{Cr}$ and $\mathrm{Ru}$ catalysts have been reported to proceed via the $s$-cis $\eta^{4}$ complex/metallacyclopentene, delivering single olefin isomers (Scheme 4). ${ }^{13}$ The configuration of the tetrasubstituted olefin would be controlled by the structure of the coupling partners and the reduction mechanism. While the first reports on diene semihydrogenation date back to the 1960s, there is only one report, by Shibasaki, for the synthesis of a tetrasubstituted olefin (trialkyl-substituted acrylonitrile) in a complex structure via semihydrogenation of a 1,3 -diene. ${ }^{13 b}$ This report predates coupling chemistry, and numerous steps were required to access the 1,3-diene. The combination of modern $\mathrm{sp}^{2}-\mathrm{sp}^{2}$ cross-coupling reactions and 1,4-semihydrogenation would allow for rapid access to a tetrasubstituted olefin in a stereodefined manner (Scheme 4). 
Scheme 4. Conceptual Approach to Tetrasubstituted Olefin Synthesis via Cross-Coupling and 1,4-Semihydrogenation

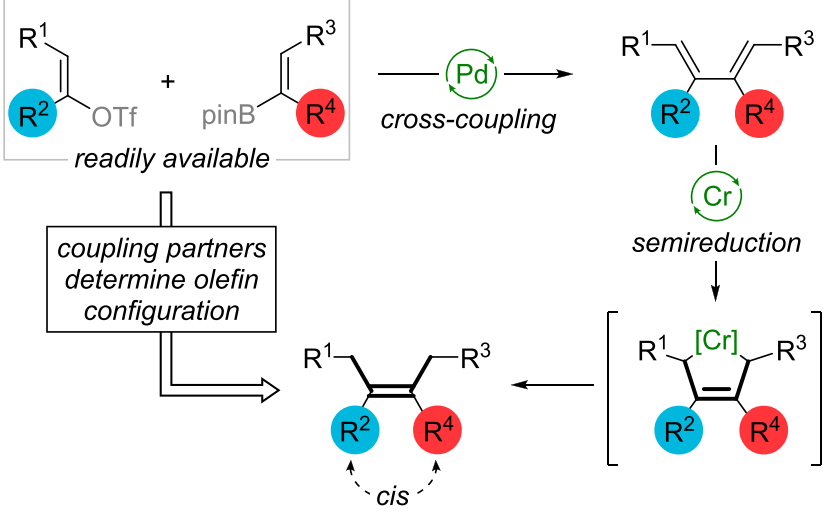

To study this approach, we prepared a series of dienes 20 via Suzuki cross-coupling ${ }^{14}$ of vinyl boronates 18 with vinyl triflates 19 and subjected them to semihydrogenation conditions (Table 1$).{ }^{15}$ We selected $\left[\mathrm{Cr}(\mathrm{CO})_{3}\left(\eta^{6}-\mathrm{MeOBz}\right)\right]$ as the catalyst for the 1,4-semihydrogenation over $\mathrm{Cp}^{*} \mathrm{Ru}$ based catalysts as very high yields and stereoselectivities have been reported for the application of this catalyst and it is readily accessible in one step from commercially available $\mathrm{Cr}(\mathrm{CO})_{6}$ and $\mathrm{MeOBz} .{ }^{13 \mathrm{~d}} \mathrm{We}$ focused on tetrasubstituted olefins featuring the same stereochemical challenges as encountered in the natural product. As the design of the cross-coupling partners determines the olefin geometry, varying the coupling partners allows for the selective preparation of both olefin isomers. Accordingly, both olefin isomers $21 \mathrm{a}$ and $\mathbf{2 1 b}$ as well as $\mathbf{2 1 c}$ and $21 \mathrm{~d}$ could be prepared in high stereoselectivities and yields from the corresponding vinyl triflates and boronates. For 21c and 21d, the olefin geometries were confirmed by 2D NOESY NMR experiments (see SI for details). The ketone in 21e was well tolerated under cross-coupling and hydrogenation conditions (97\% and 95\% yield, respectively). Also, styrenes $\mathbf{2 1 f}$ and $\mathbf{2 1 g}$ could be prepared selectively. Next, we turned our attention to the synthesis of tetrasubstituted olefins on the tricyclo[3.2.1.0 $\left.0^{2,7}\right]$ octane scaffold. In a first attempt, a symmetric isopropylidene substituent could be installed successfully (21h). During the cross-coupling reaction, most of the silyl ether was cleaved and the alcohol was reprotected prior to hydrogenation. Employing more complex vinyl boronates, $\mathbf{2 1 i}$ and $\mathbf{2 1} \mathbf{j}$ were synthesized stereoselectively. Changing the protecting group to pivalate was well tolerated under both cross-coupling and hydrogenation conditions, and $21 \mathrm{k}$ was obtained in $96 \%$ over two steps. All hydrogenation reactions were initially performed using $20 \mathrm{~mol} \%$ catalyst. This led to incomplete conversion for $21 \mathrm{e}, 21 \mathrm{~g}, 21 \mathrm{j}$, and $21 \mathrm{k}$. Increasing the catalyst loading to 50 mol\% ensured full conversion for these substrates. All tetrasubstituted olefins 21 were obtained in $>20: 1 d r$. In most cases, only traces of regioisomeric olefins $(<5 \%)$ were observed. For $21 \mathrm{c}$, decreasing the catalyst loading to $5 \mathrm{~mol} \%$ led to $54 \%$ conversion after $18 \mathrm{~h}$. After the reaction time was increased to $42 \mathrm{~h}$, full conversion and $89 \%$ yield was observed showing that the catalyst is still active after the standard

Table 1. Synthesis of Tetrasubstituted Olefins via Cross-Coupling and Semihydrogenation

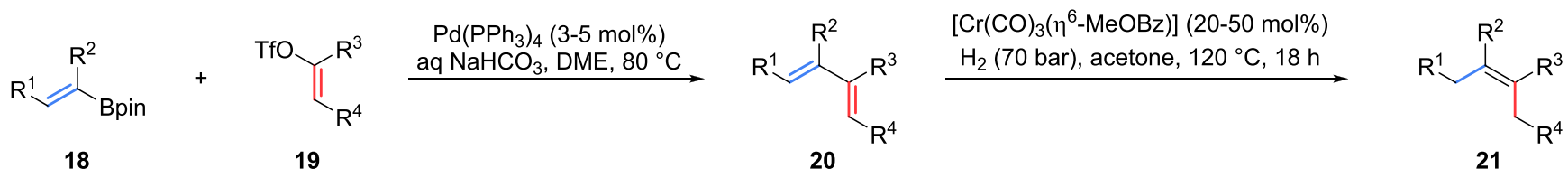

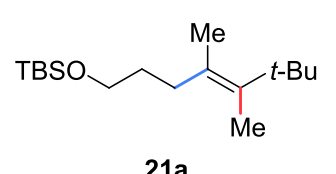

$21 \mathrm{a}$

Step 1: $98 \%$

Step 2: $94 \%^{a}$<smiles>CC(CCCOS(=O)(=O)c1ccccc1)=C1CC(C)(C)CC(=O)C1(C)C</smiles>

21e

Step 1: $97 \%$ Step 2: $95 \%^{\mathrm{b}}$

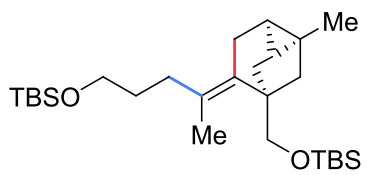

21i

Step 1: $68 \%^{\mathrm{d}}$

Step 2: $90 \%{ }^{a}$

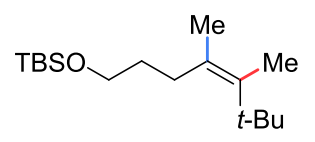

21b

Step 1: $67 \%$

Step 2: $87 \%^{\mathrm{a}}$

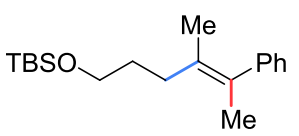

$21 f$

Step 1: $79 \%$

Step 2: $93 \%{ }^{a}$

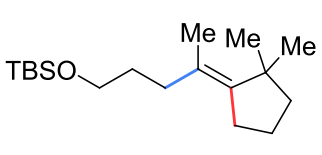

21c

Step 1: $99 \%$

Step 2: $90 \%^{\mathrm{a}}\left(89 \%^{\mathrm{c}}\right)$<smiles>CC(C)=C(C)c1ccccc1</smiles>

21g

Step 1: $79 \%$ Step 2: $84 \%^{\mathrm{b}}$

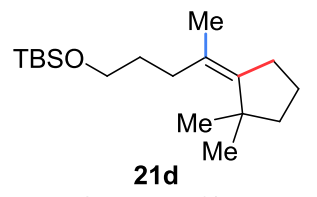

Step 1: $75 \%$

Step 2: $87 \%^{\mathrm{a}}$<smiles>CC(C)=C1CC2CCC1(C[OH+]S)CC2(C)C</smiles>

21h

Step 1: $65 \%$ d

Step 2: $92 \%^{a}$

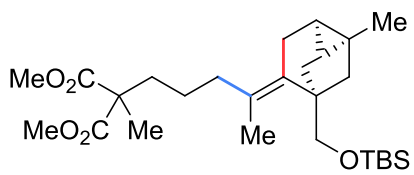

21j

Step 1: $62 \%{ }^{\mathrm{d}}$

Step 2: $97 \%^{\mathrm{b}}$<smiles>COCC(C)(CCC/C(C)=C1\CC2C=CC1(COP)CC2C)C(OC)OC</smiles>

$21 \mathbf{k}$

Step 1: $98 \%$

Step 2: $98 \%^{\mathrm{b}}$

$a_{20}$ mol\% catalyst was used. ${ }^{b} 50$ mol\% catalyst was used. ${ }^{c} 5$ mol\% catalyst was used for $42 \mathrm{~h} .{ }^{d}$ During the cross-coupling, most of the silyl ether was cleaved and was reformed using TBSCl, imidazole and DMAP (10-20 mol\%) in $\mathrm{CH}_{2} \mathrm{Cl}_{2}$ at r.t. The yields refer to combined yields over two steps. 
Scheme 5. Synthesis of Isoxazoline 26 via Nitrile Oxide Cycloaddition ${ }^{a}$

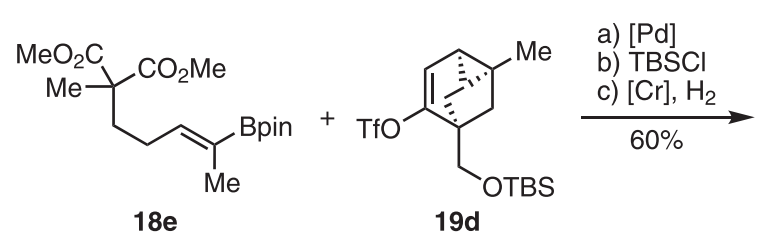

18 (1) 19d

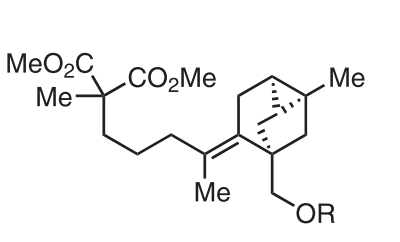

21j $(R=T B S)$ $21 \mathrm{j}(\mathrm{R}=\mathrm{TBS})$
$22(\mathrm{R}=\mathrm{H})$ e) PLE

f) $\mathrm{TBSCl}$

g) $\mathrm{ClCO}_{2} \mathrm{Me}$; $\mathrm{NaBH}_{4}$

$68 \%$

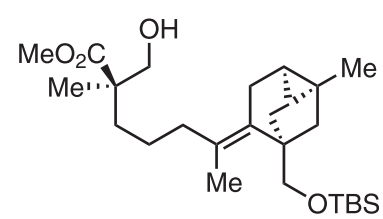

23 $58 \% \mid \begin{aligned} & \text { h) } \mathrm{DMP} \\ & \text { i) } \mathrm{H}_{2} \mathrm{NOH}\end{aligned}$

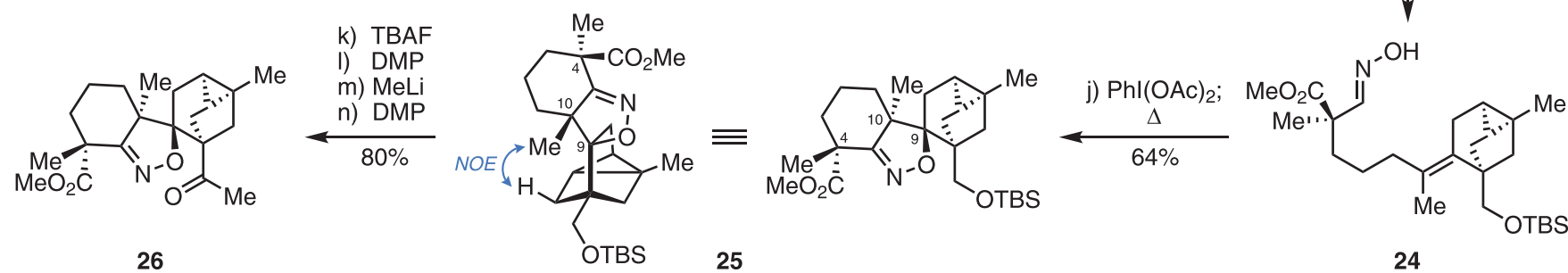

26

25

${ }^{a}$ Reagents and conditions: (a) $\mathrm{Pd}\left(\mathrm{PPh}_{3}\right)_{4}(3 \mathrm{~mol} \%), \mathrm{NaHCO}_{3}, \mathrm{DME}-\mathrm{H}_{2} \mathrm{O}$ (9:1), $80{ }^{\circ} \mathrm{C}$, then $\mathrm{HCl}, \mathrm{MeOH}$, r.t., $66 \%$; (b) TBSCl, imidazole, DMAP (20 mol\%), $\mathrm{CH}_{2} \mathrm{Cl}_{2}$, r.t., 94\%; (c) $\mathrm{H}_{2}$ (70 bar), [Cr(CO) $\left.{ }_{3}\left(\eta^{6}-\mathrm{MeOBz}\right)\right](50 \mathrm{~mol} \%)$, acetone, $120{ }^{\circ} \mathrm{C}, 97 \%$; (d) TBAF, THF, r.t., $91 \%$; (e) pig liver esterase (PLE), aq $\mathrm{NaOH}, 0.1 \mathrm{M} \mathrm{pH} 7$ sodium phosphate buffer-DMSO (10:1), r.t., $d r=20: 1$; (f) $\mathrm{TBSCl}$, imidazole, $\mathrm{DMAP} \mathrm{CH}_{2} \mathrm{Cl}_{2}$, r.t.; $\mathrm{K}_{2} \mathrm{CO}_{3}$, MeOH-THF- $\mathrm{H}_{2} \mathrm{O}(20: 10: 3)$, r.t.; (g) $\mathrm{ClCO}_{2} \mathrm{Me}, \mathrm{Et}_{3} \mathrm{~N}$, THF, $0{ }^{\circ} \mathrm{C}$ to r.t.; $\mathrm{NaBH}_{4}, \mathrm{MeOH}, 0{ }^{\circ} \mathrm{C}$, $68 \%$ over three steps; (h) DMP, $t$ - $\mathrm{BuOH}, \mathrm{CH}_{2} \mathrm{Cl}_{2}$, r.t., $71 \%$; (i) $\mathrm{H}_{2} \mathrm{NOH} \cdot \mathrm{HCl}$, $\mathrm{EtOH}-$ pyr $(8: 1)$, r.t., $82 \%$; (j) $\mathrm{PhI}(\mathrm{OAc}){ }_{2}, \mathrm{MeOH}, 0{ }^{\circ} \mathrm{C}$; PhMe, $\Delta, 64 \%$; (k) TBAF, THF, $60{ }^{\circ} \mathrm{C}$, 99\%; (l) DMP, $t$-BuOH, $\mathrm{CH}_{2} \mathrm{Cl}_{2}$, r.t., $86 \%$; (m) MeLi, THF- $\mathrm{Et}_{2} \mathrm{O}(3: 1),-78{ }^{\circ} \mathrm{C}$; (n) DMP, $t$ - $\mathrm{BuOH}, \mathrm{CH}_{2} \mathrm{Cl}_{2}$, r.t., $94 \%$ over two steps.

reaction time. Decreasing the $\mathrm{H}_{2}$ pressure to 55 bar completely shut down the reaction. Notably, variation of the concentration between 7 and $50 \mathrm{mM}$ and scaling-up the reaction to $2.3 \mathrm{mmol}$ for $21 \mathbf{j}$ had no effect on yield or stereoselectivity.

We continued our efforts toward the synthesis of $(-)$-mitrephorone A (1) using $\mathbf{2 1} \mathbf{j}$, which was prepared from vinyl boronate 18e and vinyl triflate 19d (Scheme 5). For malonate desymmetrization, we turned to the application of biocatalysis for the stereoselective monohydrolysis of $\alpha, \alpha$-disubstituted malonate $\mathbf{2 1 j}$. Subjecting malonate $\mathbf{2 1 j}$ to pig liver esterase (PLE) in a mixture of aqueous phosphate buffer and DMSO (10:1) did not lead to any conversion of starting material. ${ }^{16}$ In contrast, after silyl ether cleavage with TBAF, the corresponding malonic acid monoester was obtained in 20:1 $d r$ under the same reaction conditions. Reprotection of the hydroxy group with $\mathrm{TBSCl}$ and chemoselective reduction of the carboxylic acid to the corresponding alcohol $\left(\mathrm{ClCO}_{2} \mathrm{Me}\right.$ followed by $\mathrm{NaBH}_{4}$ ) afforded alcohol 23 in $68 \%$ from malonate $22 .{ }^{17}$ Oxime 24 was obtained via oxidation with DMP and treatment with hydroxylamine hydrochloride in $58 \%$ yield over two steps. Subjecting 24 to $\mathrm{PhI}(\mathrm{OAc})_{2}$ led to its oxidation to the corresponding nitrile oxide, ${ }^{18}$ which underwent cycloaddition to give isoxazoline $\mathbf{2 5}$ in $64 \%$ yield as a single diastereomer as determined by analysis of the ${ }^{1} \mathrm{H}$ NMR spectrum. The relative configuration was established by $1 \mathrm{D}$ NOE NMR experiments (see SI for details). It is worth noting that the cycloaddition sets two challenging stereocenters, namely the vicinal tertiary ether and quaternary center concomitant with 6-membered ring formation. Notably, when a 1:1 mixture of diastereomers of oxime 24 (epimeric at $\mathrm{C}_{4}$ ) was subjected to the reaction conditions, two diastereomers were obtained that have the same relative configuration at $\mathrm{C}_{4}, \mathrm{C}_{9}$, and $\mathrm{C}_{10}$ as determined by X-ray crystallography (see SI for details). This clearly shows that the facial selectivity in the dipolar cycloaddition is fully controlled by the $\alpha$ stereocenter of the nitrile oxide.

Examination of putative transition states as shown for $\mathbf{I}$ and II in Figure 1 proves instructive. Transition state I,

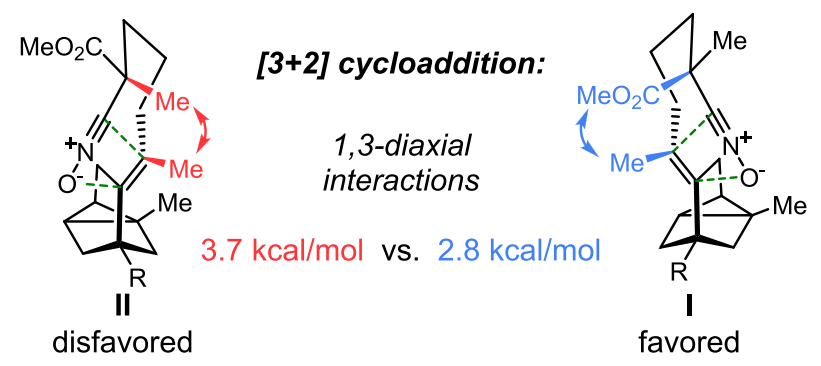

Figure 1. Putative transition states for nitrile oxide cycloaddition.

incorporating a 1,3-diaxial interaction between an ester and a methyl group, is energetically favored over transition state II, in which a 1,3-dimethyl axial interaction is present $(\sim 2.8$ vs $\sim 3.7 \mathrm{kcal} / \mathrm{mol}){ }^{19}$ This is consistent with the formation of a single diastereomer as observed by ${ }^{1} \mathrm{H}$ NMR spectroscopy.

A common problem in nitrile oxide cycloaddition is dimerization of the nirile oxide, and it has been shown that cycloreversion can be induced by heating. ${ }^{20}$ However, we did not observe any dimer, and all byproducts were highly polar baseline compounds, which could not be characterized.

Despite being scalable and relatively high yielding $(7.6 \%$ over 16 steps from 12), we aimed to further optimize the route toward isoxazoline 26 with respect to the following points: (1) Achiral vinyl boronate $18 \mathrm{e}$ could be replaced by a chiral, enantioenriched analogue 27, which would render the synthesis more convergent (Scheme 6). It is important to note that the $d r$ of coupling product 28 will depend on the ee of vinyl boronate 27. (2) The protecting group strategy is suboptimal: The TBS ether in vinyl triflate $19 \mathrm{~d}$ is cleaved during cross-coupling and was reprotected for hydrogenation but enzymatic desymmetrization only proceeded with the free alcohol. So again a sequence of deprotection, desymmetrization, and reprotection had to be carried out. Transformation of the alcohol to the corresponding methyl ketone prior to crosscoupling may improve the synthesis. 
Scheme 6. Envisioned Optimization of the Route

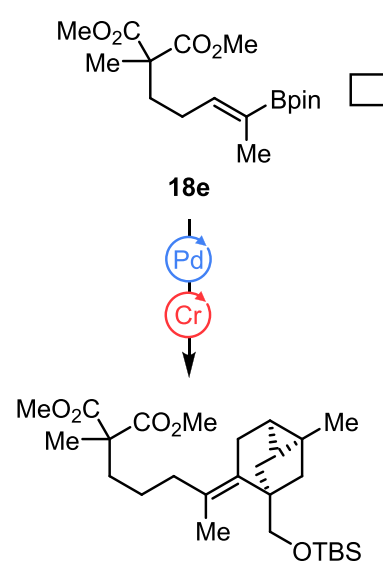

21j

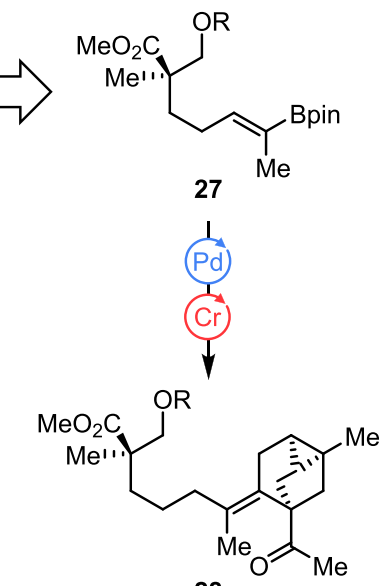

28
Malonate Desymmetrization Studies. For the asymmetric synthesis of enantioenriched vinyl boronate 27, we wanted to further explore the stereoselective monohydrolysis of $\alpha, \alpha$-disubstituted malonates. Previous studies on desymmetrization of 2-methyl-2-alkylmalonates 29 have shown that the length of $\mathrm{R}$ has a strong effect on the enantioselectivity in the hydrolysis to give $30 .{ }^{21}$ Accordingly, we prepared a series of malonates $29 a-f$, which vary in length and nature of side chain and, after enzymatic transformation, could all be elaborated to 7 (Table 2). ${ }^{2,23}$ Dimethyl malonates 29 may be conveniently

Table 2. Enzymatic Desymmetrization of Malonates $29^{a}$

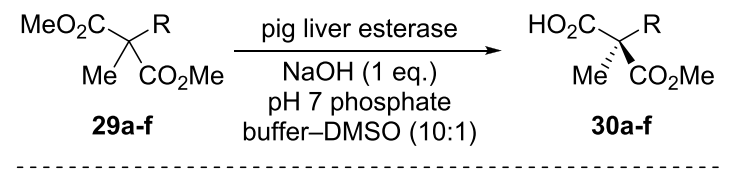

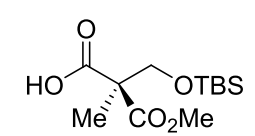

30 a $(39 \%, 95 \%$ ee* $)$<smiles>CC#CCC[C@](C)(OC)C(=O)O</smiles>

30 c $\left(74 \%, 20 \% e e^{*}\right)$<smiles>CO[C@](C)(CCC[OH+])C(=O)O</smiles>

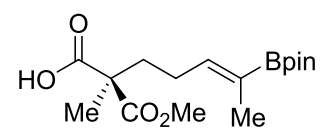

30b $(9 \%, 75 \%$ ee*)<smiles>C=CCC[C@](C)(C(C)=O)C(=O)O</smiles>

$30 \mathrm{~d}(97 \%, 23 \%$ ee* $)$

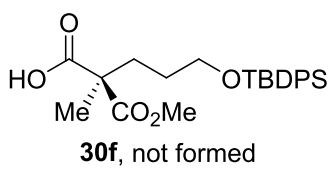

${ }^{a}$ Enantiomeric excesses (ee) were determined by analysis of the ${ }^{1} \mathrm{H}$ NMR spectra after amide coupling with enantiopure $(S)$-phenylethanamine, see SI for details. ${ }^{25}$

prepared by alkylation reactions. ${ }^{24}$ For rapid determination of enantioselectivities in our study, we developed a quick assay involving coupling of acids $\mathbf{3 0}$ with $(S)$-phenylethanamine to the corresponding diastereomeric amides. ${ }^{25}$ To benchmark the method, we repeated the pig liver esterase-mediated hydrolysis of TBS-protected 2-methyl-2-hydroxymethylmalonate 29a, which has been previously reported by Keese. ${ }^{16}$ The enantiomeric excess we observed for the formation of 30a was in full agreement with Keese's result ( $95 \%$ ee). When we subjected vinyl boronate $\mathbf{2 9 b}$ to the enzymatic step, low yield (9\%) and modest enantioselectivity $(75 \%$ ee) were observed. Consequently, we examined the enzymatic reaction with 29c and 29d, which furnished products in $74 \%$ and $97 \%$ yield, respectively, albeit in low enantiomeric excess, $20 \%$ and $23 \%$ $e e$, respectively. Examination of silyl ethers 29e and $29 \mathrm{f}$ revealed that the former afforded $30 \mathrm{e}$ in $67 \%$ yield and the highest enantiomeric excess, namely $>95 \%$ ee. Interestingly, no reaction was observed for the analogous TBDPS-protected substrate 29f. ${ }^{26}$ As a consequence of its high yield and enantiomeric excess, 30e was selected for further studies. Based on previous investigations, the absolute configuration of carboxylic acid 30e was tentatively assigned as $(R) .^{16,21}$

Synthesis of Vinyl Boronate 33. Enantiopure ${ }^{27,28}$ malonic acid monoester 30e was transformed into silyl ether 31 via chemoselective reduction of the carboxylic acid to the corresponding alcohol $\left(\mathrm{ClCO}_{2} \mathrm{Me}\right.$ followed by $\left.\mathrm{NaBH}_{4}\right),{ }^{17}$ and TBDPS protection in $61 \%$ yield from 29e (Scheme 7 ).

Scheme 7. Synthesis of Vinyl Boronate $33^{a}$

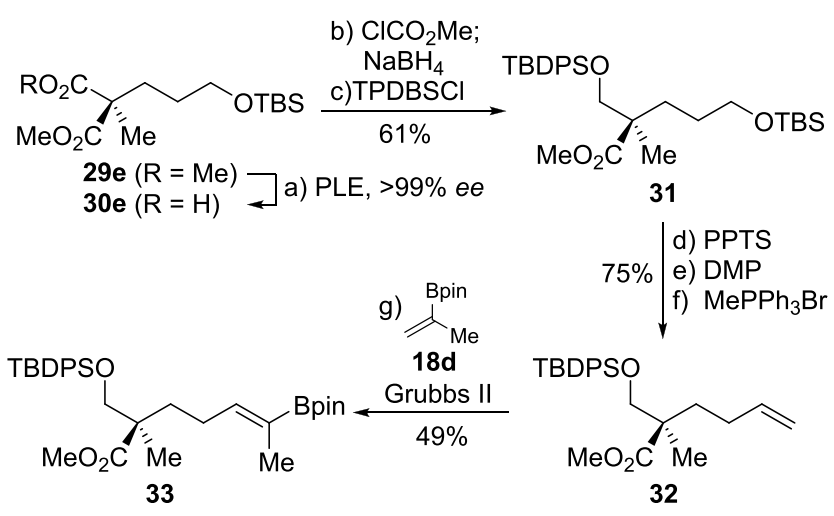

${ }^{a}$ Reagents and conditions: (a) pig liver esterase (PLE), aq $\mathrm{NaOH}, 0.1$ $\mathrm{M} \mathrm{pH} 7$ sodium phosphate buffer-DMSO (10:1), r.t.; (b) $\mathrm{ClCO}_{2} \mathrm{Me}$, $\mathrm{Et}_{3} \mathrm{~N}$, THF, $0{ }^{\circ} \mathrm{C}$ to r.t.; $\mathrm{NaBH}_{4}, \mathrm{MeOH}, 0{ }^{\circ} \mathrm{C}, 64 \%$ from 29e; (c) TBDPSCl, imidazole, DMAP (20 mol\%), $\mathrm{CH}_{2} \mathrm{Cl}_{2}$, r.t., 95\%; (d) PPTS (20 mol\%), EtOH, r.t.; (e) DMP, $t$-BuOH, $\mathrm{CH}_{2} \mathrm{Cl}_{2}$, r.t., $87 \%$ over two steps; (f) $\mathrm{MePPh}_{3} \mathrm{Br}, \mathrm{KOt}$-Bu, THF, r.t., $86 \%$; (g) isopropenylboronic acid pinacol ester $(\mathbf{1 8 d})$, Grubbs secondgeneration catalyst (10 mol\%), $\mathrm{CH}_{2} \mathrm{Cl}_{2}, 50{ }^{\circ} \mathrm{C}, 49 \%$.

Selective cleavage of the TBS-ether in 31 with PPTS in ethanol, ${ }^{29}$ subsequent oxidation with DMP, and Wittig methylenation of the resulting aldehyde afforded olefin 32 in $75 \%$ yield over three steps. Vinyl boronate 33 was prepared via cross-metathesis of $\mathbf{3 2}$ with isopropenylboronic acid pinacol ester (18d) in $49 \%$ yield. $^{23}$

Synthesis of Tetrasubstituted Olefin 37. We subsequently transformed hydroxyketone $\mathbf{1 2}^{7}$ into a suitable building block for cross coupling. Following a short sequence (Comins reagent (34); DMP; MeLi; DMP), 35 was prepared (Scheme 8). ${ }^{30}$ Cross-coupling of 35 with vinyl boronate 33 afforded 1,3-diene 36 in $65 \%$ yield. ${ }^{14}$ Intermediate 36 was subjected to hydrogenation conditions in the presence of 50 mol\% of catalyst $\left[\mathrm{Cr}(\mathrm{CO})_{3}\left(\eta^{6}-\mathrm{MeOBz}\right)\right]$. Desired tetrasubstituted olefin 37 was obtained in $93 \%$ yield as a single olefin isomer.

Completion of the Carbon Skeleton via Nitrile Oxide Cycloaddition. Silyl ether 37 was converted into oxime 38 via deprotection with TBAF, oxidation with DMP and oxime 
Scheme 8. Synthesis of Tetrasubstituted Olefin $37^{a}$<smiles>CC1CC2(CO)CCC1C(=O)C2</smiles>

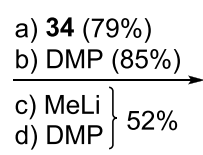

12

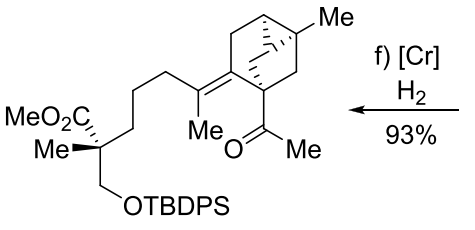

37

single isomer

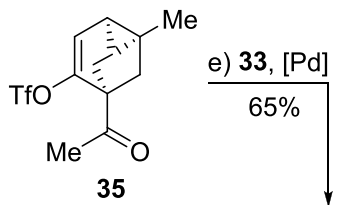

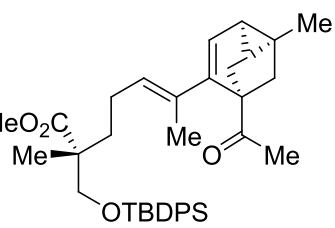

36
${ }^{a}$ Reagents and conditions: (a) TMSCl, imidazole, $\mathrm{THF}$, r.t., then $\mathrm{KHMDS},-78{ }^{\circ} \mathrm{C}$, then Comins reagent $(34),-78^{\circ} \mathrm{C}$, then aq $\mathrm{HCl}$, r.t., 79\%; (b) $\mathrm{DMP}, t-\mathrm{BuOH}, \mathrm{CH}_{2} \mathrm{Cl}_{2}$, r.t., $85 \%$; (c) $\mathrm{MeLi}$, THF, $-78{ }^{\circ} \mathrm{C}$; (d) DMP, $t$-BuOH, $\mathrm{CH}_{2} \mathrm{Cl}_{2}$, r.t., $52 \%$ over two steps; (e) 33, $\mathrm{Pd}\left(\mathrm{PPh}_{3}\right)_{4}(2.5 \mathrm{~mol} \%), \mathrm{NaHCO}_{3}, \mathrm{DME}-\mathrm{H}_{2} \mathrm{O}(9: 1), 85^{\circ} \mathrm{C}, 65 \%$; (f) $\mathrm{H}_{2}$ (70 bar), $\left[\mathrm{Cr}(\mathrm{CO})_{3}\left(\eta^{6}-\mathrm{MeOBz}\right)\right](50 \mathrm{~mol} \%)$, acetone, $120{ }^{\circ} \mathrm{C}$, $93 \%$.

formation with hydroxylamine hydrochloride in $62 \%$ yield over three steps (Scheme 9). ${ }^{6 c}$ Subjecting 38 to the same nitrile oxide cycloaddition conditions as described above afforded isooxazoline $\mathbf{2 6}$ in $52 \%$ yield as a single diastereomer along with $10 \%$ recovered starting material. No side products were observed in significant quantities ( $>5 \%$ yield). Enolization of 26 with LDA or synthesis of the corresponding trimethylsilyl enol ether followed by treatment with $\mathrm{BF}_{3} \cdot \mathrm{OEt}_{2}$ did not induce intramolecular addition to the isoxazoline. In contrast, after $\mathrm{N}$-methylation of 26 using Meerwein's salt $\left(\mathrm{Me}_{3} \mathrm{OBF}_{4}\right){ }^{31}$ the intermediate isoxazolinium salt 39 was subjected in situ to TMSOTf and $\mathrm{Et}_{3} \mathrm{~N}$ to induce cyclization. The Mannich-type reaction afforded isoxazolidine $\mathbf{4 0}$ in 69\% yield and completed the carbon skeleton of the natural product. Treatment of $\mathbf{4 0}$ with $\mathrm{Zn}$ in $\mathrm{AcOH}$ at $50{ }^{\circ} \mathrm{C}$ led to $\mathrm{N}-\mathrm{O}$ bond cleavage with concomitant methylamine elimination to give enone 41 in $65 \%$ yield. Various attempts to induce oxa-Michael addition of $\mathbf{4 1}$ and either trapping the resulting enolate as the corresponding enol ether (e.g., TBSOTf, 2,6-lutidine or proton sponge) or oxidizing it $\left(\mathrm{IPh}_{2} \mathrm{BF}_{4}, \mathrm{I}_{2} / \mathrm{NaHCO}_{3}, \mathrm{NBS} / \mathrm{NaHCO}_{3}\right.$, $\mathrm{PhI}(\mathrm{OAc})_{2} / \mathrm{KO} t-\mathrm{Bu}, \mathrm{O}_{2} / \mathrm{KO} t$-Bu, MoOPH/KHMDS) were unsuccessful. Also, oxidative transformation of the enone to the diosphenol proved unfruitful (epoxidation followed by rearrangement or dihydroxylation followed by elimination). At this point, 41 was reduced to the corresponding saturated ketone $\mathbf{4 2}$ with $\mathrm{H}_{2}$ and $\mathrm{Pd} / \mathrm{C}$ in $77 \%$ yield. ${ }^{32}$ Isoxazolidine 40 could also be directly reduced to 42 using $\mathrm{H}_{2}$ and $\mathrm{Pd} / \mathrm{C}$ in the presence of $\mathrm{AcOH}$ at $80{ }^{\circ} \mathrm{C}$ in $72 \%$ yield.

$\alpha$-Oxidation of $42\left(\mathrm{O}_{2}, \mathrm{KO} t\right.$-Bu, then $\left.\mathrm{PPh}_{3}\right)$ gave $\alpha$-hydroxyketone 43 in $72 \%$ yield (Scheme 10). ${ }^{33}$ Treatment

\section{Scheme 10. Completion of the Synthesis ${ }^{a}$}

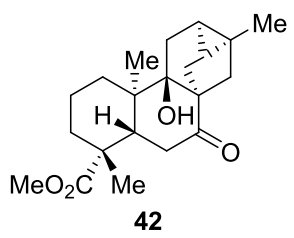

42

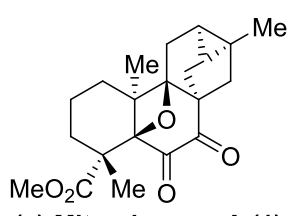

(-)-Mitrephorone A (1)

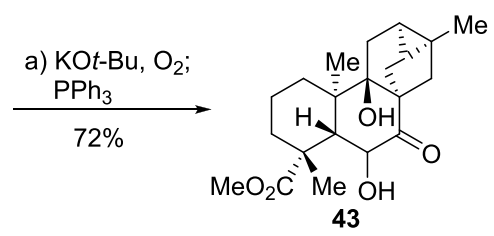

b) DMP; $\mathrm{SiO}_{2} \mid 74 \%$

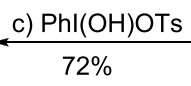

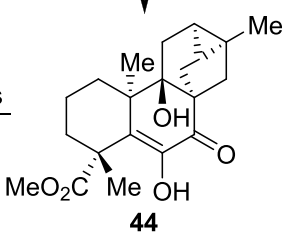

${ }^{a}$ Reagents and conditions: (a) KOt-Bu, $\mathrm{O}_{2}$, THF, $-78{ }^{\circ} \mathrm{C}$, then $\mathrm{PPh}_{3}$, $-78{ }^{\circ} \mathrm{C}$ to r.t., $72 \%$; (b) DMP, $t$ - $\mathrm{BuOH}, \mathrm{CH}_{2} \mathrm{Cl}_{2} ; \mathrm{SiO}_{2}$, hexaneEtOAc (3:1), 74\%; (c) $\mathrm{PhI}(\mathrm{OH}) \mathrm{OTs}, \mathrm{NaHCO}_{3}, \mathrm{CH}_{2} \mathrm{Cl}_{2}, 72 \%$.

with DMP furnished hydroxydiosphenol 44 in $74 \%$ yield. It is worth noting that oxidation of $\mathbf{4 2}$ to diosphenol $\mathbf{4 4}$ was carried out in an efficient sequence with the tertiary alcohol being unprotected. This was not possible in our first route employing an isomeric ketone, which necessitated protection of the tertiary alcohol as its silyl ether. ${ }^{3}$ Finally, (-)-mitrephorone A (1) was obtained via oxidative cyclization of 44 mediated by

Scheme 9. Synthesis of 42 via Nitrile Oxide Cycloaddition ${ }^{a}$

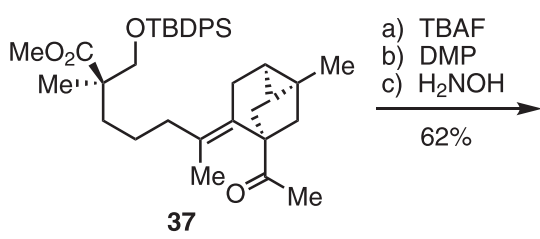

37

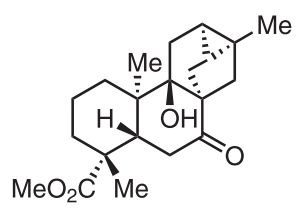

42

$\uparrow$

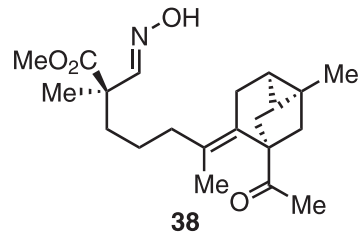

d) $\underset{\Delta}{\stackrel{\mathrm{Phl}(\mathrm{OAc})_{2} ;}{\longrightarrow}}$

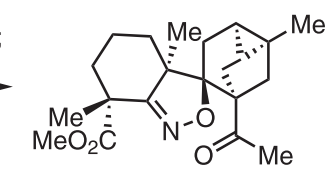
e) $\mathrm{Me}_{3} \mathrm{OBF}_{4}$

26 single isomer

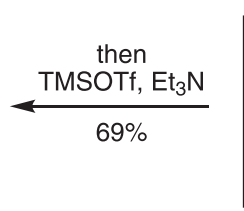

$40(\mathrm{R}=\mathrm{Me})$

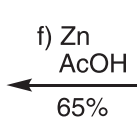

41

h) $\mathrm{H}_{2}, \mathrm{Pd} / \mathrm{C}, \mathrm{AcOH}$

$72 \%$

${ }^{a}$ Reagents and conditions: (a) TBAF, THF, r.t.; (b) DMP, $t-\mathrm{BuOH}_{1} \mathrm{CH}_{2} \mathrm{Cl}_{2}$, r.t., $73 \%$ over two steps; (c) $\mathrm{H}_{2} \mathrm{NOH} \cdot \mathrm{HCl}$, pyr-EtOH (8:1), r.t., $85 \%$; (d) $\mathrm{PhI}(\mathrm{OAc})_{2}, \mathrm{MeOH}, 0{ }^{\circ} \mathrm{C}$; $\mathrm{PhMe}, \Delta$, 52\%; (e) $\mathrm{Me}_{3} \mathrm{OBF}_{4}, \mathrm{CH}_{2} \mathrm{Cl}_{2}$, r.t., then TMSOTf, $\mathrm{Et}_{3} \mathrm{~N}$, r.t., $69 \%$; (f) $\mathrm{Zn}, \mathrm{AcOH}, 50{ }^{\circ} \mathrm{C}, 65 \%$; $(\mathrm{g}) \mathrm{H}_{2}$ $(1 \mathrm{~atm}), \mathrm{Pd} / \mathrm{C}(30 \mathrm{~mol} \%), \mathrm{EtOAc}$, r.t., $77 \%$; (h) $\mathrm{H}_{2}(1 \mathrm{~atm}), \mathrm{Pd} / \mathrm{C}, \mathrm{EtOAc}-\mathrm{AcOH}(5: 1), 80{ }^{\circ} \mathrm{C}, 72 \%$. 
Koser's reagent $(\mathrm{PhI}(\mathrm{OH}) \mathrm{OTs})$ in the presence of $\mathrm{NaHCO}_{3}$ in $72 \%$ yield and $>99 \%$ ee, which compares favorably with previous total syntheses ( 88 and $85 \%$ ee). ${ }^{3,4 a, 34,35}$ Spectroscopic data of the material we obtained is identical with that reported for the natural isolate. ${ }^{2}$

\section{CONCLUSION}

We have reported a highly enantioselective and diastereoselective total synthesis of $(-)$-mitrephorone A $(1,>99 \%$ ee $)$. The synthesis relies on intramolecular nitrile oxide cycloaddition, which sets two stereocenters, forms one all-carbon ring and introduces an isoxazoline, which serves as a handle for elaboration of the cycloadduct to the natural product. Additional salient features of the synthesis include highly enantioselective pig liver esterase-catalyzed malonate desymmetrization, 1,4-semihydrogenation of a 1,3-diene, and hypervalent iodine-mediated oxidative cyclization to furnish the oxetane. Stereo- and regioselective synthesis of tetrasubstituted double bonds via $\mathrm{sp}^{2}-\mathrm{sp}^{2}$ cross-coupling and 1,4-semihydrogenation has no precedence and represents a powerful method for olefin synthesis.

\section{ASSOCIATED CONTENT}

\section{SI Supporting Information}

The Supporting Information is available free of charge at https://pubs.acs.org/doi/10.1021/jacs.0c09520.

Experimental procedures and characterization data for all new compounds (PDF)

Crystallographic data for a mixture of $\mathbf{2 5}$ and its diastereomer S6 (CIF)

\section{AUTHOR INFORMATION}

\section{Corresponding Author}

Erick M. Carreira - ETH Zürich, 8093 Zürich, Switzerland; (ㄱ) orcid.org/0000-0003-1472-490X;

Email: erickm.carreira@org.chem.ethz.ch

\section{Authors}

Michael Schneider - ETH Zürich, 8093 Zürich, Switzerland; (1) orcid.org/0000-0001-8519-6505

Matthieu J. R. Richter - ETH Zürich, 8093 Zürich, Switzerland; ○ orcid.org/0000-0001-7957-3474

Complete contact information is available at:

https://pubs.acs.org/10.1021/jacs.0c09520

\section{Funding}

This work was funded by the European Research Council (OLECAT, Grant-ID 833540).

\section{Notes}

The authors declare no competing financial interest.

\section{ACKNOWLEDGMENTS}

We thank Ján Kovacovic for assistance with high-pressure reactions.

\section{REFERENCES}

(1) Fraga, B. M. The Trachylobane Diterpenes. Phytochem. Anal. 1994, 5, 49-56.

(2) Li, C.; Lee, D.; Graf, T. N.; Phifer, S. S.; Nakanishi, Y.; Burgess, J. P.; Riswan, S.; Setyowati, F. M.; Saribi, A. M.; Soejarto, D. D.; Farnsworth, N. R.; Falkinham, J. O., III; Kroll, D. J.; Kinghorn, A. D.; Wani, M. C.; Oberlies, N. H. A Hexacyclic ent-Trachylobane
Diterpenoid Possessing an Oxetane Ring from Mitrephora glabra. Org. Lett. 2005, 7, 5709-5712.

(3) Richter, M. J. R.; Schneider, M.; Brandstätter, M.; Krautwald, S.; Carreira, E. M. Total Synthesis of (-)-Mitrephorone A. J. Am. Chem. Soc. 2018, 140, 16704-16710.

(4) (a) Wein, L. A.; Wurst, K.; Angyal, P.; Weisheit, L.; Magauer, T. Synthesis of (-)-Mitrephorone A via a Bioinspired Late Stage C-H Oxidation of (-)-Mitrephorone B. J. Am. Chem. Soc. 2019, 141, 19589-19593. Very recently, Renata and co-workers reported a semisynthetic approach to (-)-mitrephorone A: (b) Zhang, X.; KingSmith, E.; Dong, L.-B.; Yang, L.-C.; Rudolf, J. D.; Shen, B.; Renata, H. Divergent synthesis of complex diterpenes through a hybrid oxidative approach. Science 2020, 369, 799-806.

(5) Zgoda-Pols, J. R.; Freyer, A. J.; Killmer, L. B.; Porter, J. R. Antimicrobial diterpenes from the stem bark of Mitrephora celebica. Fitoterapia 2002, 73, 434-438.

(6) For a discussion on nitrile oxide cycloaddition followed by reductive cleavage for the synthesis of $\beta$-hydroxyketones, see: (a) Bode, J. W.; Carreira, E. M. Stereoselective Syntheses of Epothilones A and B via Directed Nitrile Oxide Cycloaddition. J. Am. Chem. Soc. 2001, 123, 3611-3612. (b) Muri, D.; Carreira, E. M. Stereoselective Synthesis of Erythronolide A via Nitrile Oxide Cycloadditions and Related Studies. J. Org. Chem. 2009, 74, 86958712. (c) Becker, N.; Carreira, E. M. Hydroxyl-Directed Nitrile Oxide Cycloaddition Reactions with Cyclic Allylic Alcohols. Org. Lett. 2007, 9, 3857-3858.

(7) Schneider, M.; Richter, M. J. R.; Krautwald, S.; Carreira, E. M. Asymmetric Synthesis of the Tricyclooctane Core of Trachylobane Natural Products and Related Terpenoids. Org. Lett. 2019, 21, 87058707.

(8) Wittig and Horner-Wadsworth-Emmons olefinations have previously been shown to suffer from low reactivity and stereoselectivity in the formation of tetrasubstituted double bonds. In our studies, we were able to react the tricyclooctanone with methyltriphenylphosphonium bromide or diethyl cyanomethylphosphonate, but the obtained di- or trisubstituted olefins could not be transformed into tetrasubstituted olefins. For a review on the synthesis of tetrasubstituted olefins, including Wittig and Horner-WadsworthEmmons olefinations of carbonyls, see: Flynn, A. B.; Ogilvie, W. W. Stereocontrolled Synthesis of Tetrasubstituted Olefins. Chem. Rev. 2007, 107, 4698-4745.

(9) Casimiro-Garcia, A.; Micklatcher, M.; Turpin, J. A.; Stup, T. L.; Watson, K.; Buckheit, R. W.; Cushman, M. Novel Modifications in the Alkenyldiarylmethane (ADAM) Series of Non-Nucleoside Reverse Transcriptase Inhibitors. J. Med. Chem. 1999, 42, 4861-4874.

(10) (a) Wipf, P. Claisen Rearrangements. Comprehensive Organic Synthesis; Pergamon Press: Oxford, 1991; Vol. 5, pp 827-873. (b) Ziegler, F. E. The Thermal, Aliphatic Claisen Rearrangement. Chem. Rev. 1988, 88, 1423-1452.

(11) Clark, D. A.; Kulkarni, A. A.; Kalbarczyk, K.; Schertzer, B.; Diver, S. T. Tandem Enyne Metathesis and Claisen Rearrangement: A Versatile Approach to Conjugated Dienes of Variable Substitution Patterns. J. Am. Chem. Soc. 2006, 128, 15632-15636.

(12) Wang, J.; Dong, Z.; Yang, C.; Dong, G. Modular and regioselective synthesis of all-carbon tetrasubstituted olefins enabled by an alkenyl Catellani reaction. Nat. Chem. 2019, 11, 1106-1112.

(13) (a) Frankel, E. N.; Selke, E.; Glass, C. A. Homogeneous 1,4addition of Hydrogen Catalyzed by Tricarbonyl(arene)chromium Complexes. J. Am. Chem. Soc. 1968, 90, 2446-2448. (b) Sodeoka, M.; Ogawa, Y.; Kirio, Y.; Shibasaki, M. Stereocontrolled Synthesis of Exocyclic Olefins Using Arene Tricarbonyl Chromium ComplexCatalyzed Hydrogenation. I. Efficient Synthesis of Carbacyclin and Its Analogs. Chem. Pharm. Bull. 1991, 39, 309-322. (c) Steines, S.; Englert, U.; Drießen-Hölscher, B. Stereoselective catalytic hydrogenation of sorbic acid and sorbic alcohol with new $\mathrm{Cp} * \mathrm{Ru}$ complexes. Chem. Commun. 2000, 217-218. (d) Hudecek, M.; Toma, S. A simple route to $\left(\eta^{6}\right.$-arene)tricarbonyl complexes and a systematic study of different catalysts for complexation of arenes with $\mathrm{Cr}(\mathrm{CO})_{6}$. J. Organomet. Chem. 1991, 406, 147-151. 
(14) Su, N.; Theorell, J. A.; Wink, D. J.; Driver, T. G. CopperCatalyzed Formation of $\alpha$-Alkoxycycloalkenones from $N$-Tosylhydrazones. Angew. Chem., Int. Ed. 2015, 54, 12942-12946.

(15) Vinyl boronates 18 were prepared via alkyne hydroboration or purchased from commercial sources. Vinyl triflates 19 were prepared from the corresponding ketones (see SI for details).

(16) Luyten, M.; Müller, S.; Herzog, B.; Keese, R. Enzyme-Catalyzed Hydrolysis of Some Functionalized Dimethyl Malonates. Helv. Chim. Acta 1987, 70, 1250-1254.

(17) Prantz, K.; Mulzer, J. Decarboxylative Grob-Type Fragmentations in the Synthesis of Trisubstituted $Z$ Olefins: Application to Peloruside A, Discodermolide, and Epothilone D. Angew. Chem., Int. Ed. 2009, 48, 5030-5033.

(18) Mendelsohn, B. A.; Lee, S.; Kim, S.; Teyssier, F.; Aulakh, V. S.; Ciufolini, M. A. Oxidation of Oximes to Nitrile Oxides with Hypervalent Iodine Reagents. Org. Lett. 2009, 11, 1539-1542.

(19) Corey, E. J.; Feiner, N. F. Computer-Assisted Synthetic Analysis. A Rapid Computer Method for the Semiquantitative Assignment of Conformation of Six-Membered Ring Systems. 2. Assessment of Conformational Energies. J. Org. Chem. 1980, 45, 765780.

(20) Curran, D. P.; Fenk, C. J. Thermolysis of Bis[2[(trimethylsilyl)oxy]prop-2-yl]furoxan (TOP-furoxan). The First Practical Method for Intermolecular Cycloaddition of an in Situ Generated Nitrile Oide with 1,2-Di- and Trisubstituted Olefins. J. Am. Chem. Soc. 1985, 107, 6023-6028.

(21) (a) Björkling, F.; Boutelje, J.; Gatenbeck, S.; Hult, K.; Norin, T.; Szmulik, P. Enzyme Catalysed Hydrolysis of Dialkylated Propanedioic Acid Diesters, Chain Length Dependent Reversal of Enantioselectivity. Tetrahedron 1985, 41, 1347-1352. (b) Banerjee, S.; Wiggins, W. J.; Geoghegan, J. L.; Anthony, C. T.; Woltering, E. A.; Masterson, D. S. Novel synthesis of various orthogonally protected $\mathrm{C}^{\alpha}$-methyllysine analogues and biological evaluation of a Vapreotide analogue containing $(S)$ - $\alpha$-methyllysine. Org. Biomol. Chem. 2013, 11, 6307-6319.

(22) Hesse, M. J.; Butts, C. P.; Willis, C. L.; Aggarwal, V. K. Diastereodivergent Synthesis of Trisubstituted Alkenes through Protodeboronation of Allylic Boronic Esters: Application to the Synthesis of the Californian Red Scale Beetle Pheromone. Angew. Chem., Int. Ed. 2012, 51, 12444-12448.

(23) Chatterjee, A. K.; Grubbs, R. H. Formal Vinyl C-H Activation and Allylic Oxidation by Olefin Metathesis. Angew. Chem., Int. Ed. 2002, 41, 3171-3174.

(24) Craig, D.; Funai, K.; Gore, S. J.; Kang, A.; Mayweg, A. V. W. Transannular Claisen rearrangement reactions for the synthesis of vinylcyclobutanes: formal synthesis of $( \pm)$-grandisol. Org. Biomol. Chem. 2011, 9, 8000-8002.

(25) For all malonates 29 , racemic hydrolysis with sodium hydroxide followed by coupling with $(S)$-phenylethanamine gave the corresponding amides in 1:1 dr, thus showcasing the usability of this method to determine the enantiomeric excess of the intermediate carboxylic acids. No remaining intermediate carboxylic acid was observed in ${ }^{1} \mathrm{H}$ NMR analysis of unpurified ester amides.

(26) None of the investigated malonates 29 is well soluble in the phosphate buffer. The absence of reactivity for $29 \mathrm{f}$ may be attributed to (1) lack of solubility or (2) poor fit into the enzyme pocket. The aqueous conditions required for the enzymatic resolution along with accessibility to the lipase active site result in dependences on substrate structure that are subtle.

(27) The assay used for determination of enantiomeric excesses in Table 2 has its limitations for $e e^{\prime} s>90 \%$ because the $d r$ 's of the ester amides cannot be accurately determined by ${ }^{1} \mathrm{H}$ NMR analysis. Therefore, carboxylic acid 30e was reduced to the corresponding alcohol followed by benzoylation. The enantiomeric excess was determined by chiral HPLC ( $>99 \% e e$, see SI for details).

(28) The enantiomeric excess of $30 \mathrm{e}(>99 \%$ ee) is considered as enantiopure.

(29) Prakash, C.; Saleh, S.; Blair, I. A. Selective De-Protection of Silyl Ethers. Tetrahedron Lett. 1989, 30, 19-22.
(30) Cruz, A. C. F.; Miller, N. D.; Willis, M. C. Intramolecular Palladium-Catalyzed Direct Arylation of Alkenyl Triflates. Org. Lett. 2007, 9, 4391-4393.

(31) Henneböhle, M.; Le Roy, P.-Y.; Hein, M.; Ehrler, R.; Jäger, V. Isoxazolinium Salts in Asymmetric Synthesis. 1. Stereoselective Reduction Induced by a 3'-Alkoxy Stereocentre. A new Approach to Polyfunctionalized $\beta$-Amino Acids. Z. Naturforsch., B: J. Chem. Sci. 2004, 59b, 451-467.

(32) The configuration of the newly formed stereocenter was assigned based on a ball-and-stick model of enone 41 and the directive effect of the nearby hydroxy group. For the latter, see: Thompson, H. W. Stereochemical Control of Reductions. The Directive Effect of Carbomethoxy vs. Hydroxymethyl groups in Catalytic Hydrogenation. J. Org. Chem. 1971, 36, 2577-2580.

(33) Paquette, L. A.; Hofferberth, J. E. Effect of 9,10-Cyclic Acetal Stereochemistry on Feasible Operation of the $\alpha$-Ketol Rearrangement in Highly Functionalized Paclitaxel (Taxol) Precursors. J. Org. Chem. 2003, 68, 2266-2275.

(34) For a discussion on potential mechanisms involving oxygenand carbon-bound hypervalent iodine species, see: Arava, S.; Kumar, J. N.; Maksymenko, S.; Iron, M. A.; Parida, K. N.; Fristrup, P.; Szpilman, A. M. Enolonium Species-Umpoled Enolates. Angew. Chem., Int. Ed. 2017, 56, 2599-2603.

(35) In their recent synthesis of Preuisolactone A, Trauner and coworkers used a similar reaction, in which they formed a $\gamma$-lactone via oxidative cyclization of a carboxylic acid and a diosphenol. Novak, A. J. E.; Grigglestone, C. E.; Trauner, D. A Biomimetic Synthesis Elucidates the Origin of Preuisolactone A. J. Am. Chem. Soc. 2019, $141,15515-15518$. 